\title{
Tratamentos silviculturais e volume de madeira em uma área experimental de floresta nativa na Jari, Amapá
}

A necessidade de aplicar tratamentos silviculturais e a falta de estudos baseados na ecologia das comunidades tem motivado os pesquisadores a desenvolverem novas técnicas a um custo mais baixo e com melhores resultados. O objetivo do trabalho é analisar o efeito dos tratamentos silviculturais sobre a dinâmica volumétrica de espécies arbóreas comerciais e não comerciais após a exploração florestal em uma área experimental da Embrapa Amazônia Oriental no município de Vitória do Jari, Amapá. O experimento foi iniciado em $1983 \mathrm{com}$ inventário pré-exploratório. As médias das classes de volumes foram comparadas através do teste Tukey ao nível de 5\% de probabilidade. Em 20 anos de estudo, verificou-se que não houve diferença significativa entre as médias e comparando 1984 com 2011 o volume aumentou em 1,2\% ultrapassando o volume inicial. A floresta recuperou o volume total em menos de um ciclo de corte de 35 anos, entretanto, o baixo número de espécies comerciais exploradas, que não conseguem recuperar o volume comercial e área basal, atreladas ao baixo rendimento no seu processamento na indústria, faz com que essas espécies demorem mais tempo para serem exploradas elevando o ciclo de corte para acima de 35 anos. Espécies valiosas no mercado com baixa abundância e crescimento lento podem desaparecer em um futuro próximo se não receberem uma atenção maior nos planos de manejo florestal. Portanto, devem-se estabelecer ciclos de corte adequados para cada espécie florestal.

Palavras-chave: Exploração de Impacto Reduzido; Ciclo de Corte; Redução de Área Basal.

\section{Forest treatments and wood volume in an experimental forest area in Jari, Amapá}

\begin{abstract}
The need to apply silvicultural treatments and the lack of studies based on community ecology has motivated researchers to develop new techniques at a lower cost and with better results. The objective of this work is to analyze the effect of silvicultural treatments on the volumetric dynamics of commercial and noncommercial tree species after logging in an experimental area of Embrapa Eastern Amazon in Vitória do Jari, Amapá. The experiment was started in 1983 with preexisting inventory exploratory. Volume class means were compared by Tukey test at $5 \%$ probability level. In 20 years of study, it was found that there was no significant difference between the means and comparing 1984 with 2011 the volume increased by $1.2 \%$ exceeding the initial volume. The forest recovered its total volume in less than a 35-year cutting cycle, however, the low number of commercially exploited species, which are unable to recover the commercial volume and basal area, coupled with the low yield in their processing in industry, makes that these species take longer to be explored by raising the cutting cycle to over 35 years. Valuable species on the market with low abundance and slow growth may disappear in the near future if not given greater attention in forest management plans. Therefore, appropriate felling cycles should be established for each forest species.
\end{abstract}

Keywords: Impact of Reduced exploration; Cycle cutting; Basal Area Reduction.

Topic: Ciências Florestais

Reviewed anonymously in the process of blind peer.
Received: 02/10/2019

Approved: 26/11/2019
Klewton Adriano Oliveira Pinheiro (ic Instituto Federal do Pará, Brasil http://lattes.cnpq.br/8139678842009696 http://orcid.org/0000-0003-2696-4249 klewton.pinheiro@gmail.com

\section{Ademir Roberto Ruschel (iD)}

Embrapa Amazônia Oriental, Brasil

http://lattes.cnpq.br/6636714035510120

http://orcid.org/0000-0002-0352-5238

ademir.ruschel@embrapa.br

Francisco de Assis Oliveira (iD

Universidade Federal Rural da Amazônia, Brasil http://lattes.cnpq.br/4380083085706495 http://orcid.org/0000-0002-4720-3492 fdeassis@gmail.com
Francimary da Silva Carneiro (iD) Embrapa Amazônia Oriental, Brasil http://lattes.cnpq.br/8657235544233319 http://orcid.org/0000-0002-1693-8779 francimarycarneiro@gmail.com

Larissa Martins Barbosa D'Arace (1D Embrapa Amazônia Oriental, Brasil http://lattes.cnpq.br/1315133297466306 http://orcid.org/0000-0002-8533-555X larissamartins350@gmail.com

\section{Felix Lélis da Silva (D)}

Instituto Federal do Pará, Brasil http://lattes.cnpq.br/9453209743354574 http://orcid.org/0000-0002-4076-9696 lixlellis@yahoo.com.br
Alex da Silva Frazão (iD

Faculdade de Ciências Agrárias do Pará, Brasil http://lattes.cnpq.br/4115242311079453 http://orcid.org/0000-0002-1280-9275 frazaoflorestal@gmail.com

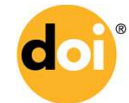

DOI: 10.6008/CBPC2179-6858.2019.006.0006
Referencing this:

PINHEIRO, K. A. O.; RUSCHEL, A. R.; OLIVEIRA, F. A.; CARNEIRO, F. S.; D'ARACE, L. M. B.; SILVA, F. L.; FRAZÃO, A. S.. Tratamentos silviculturais e volume de madeira em uma área experimental de floresta nativa na Jari, Amapá. Revista Ibero Americana de Ciências Ambientais, v.10, n.6, p.50-66, 2019. DOI:

http://doi.org/10.6008/CBPC2179-6858.2019.006.0006 


\section{INTRODUÇÃO}

As florestas tropicais da Amazônia brasileira possuem alta diversidade de espécies com indivíduos distribuídos em vários estratos e com idades e tamanhos diferentes que possuem características ecofisiológicas distintas, tornando-os difíceis de manejar (VATRAZ et al., 2012). As empresas madeireiras só consideram a madeira e o extrativismo como os recursos mais importantes esquecendo que a fauna e flora, a utilização de plantas para fabricação de fármacos e exploração turística também oferece ilimitadas possibilidades comerciais ainda pouco exploradas. As florestas também oferecem serviços ecológicos indiretos, como a regulação da disponibilidade e da qualidade das águas, a estabilidade climática, a redução da concentração de poluentes atmosféricos e a própria preservação do solo quando se garante a sua sustentabilidade. $O$ valor ecológico pode ser de igual importância quando se considera a preservação do meio ambiente em geral.

Os ecossistemas de florestas naturais apresentam complexidades que dificultam suas avaliações biológicas, principalmente os relacionados com a dinâmica de crescimento, a estrutura de floresta e com a competição entre e intra espécies. Existem inúmeros estudos publicados sobre crescimento e rendimento de florestas tropicais, e a maioria destaca apenas o povoamento florestal como um todo, sem levar em consideração o crescimento individual das espécies (SILVA et al., 2003).

A exploração florestal realizada através de métodos inadequados é frequentemente utilizada em florestas naturais em decorrência da extração ilegal de madeira, porém a sociedade vem cobrando práticas mais sustentáveis de manejo, utilizando técnicas de Exploração de Impacto Reduzido (EIR), amplamente difundida na Amazônia brasileira, uma vez que as pesquisas demonstram maior rentabilidade e efeitos menos nocivos ao meio ambiente em áreas manejadas. Uhl (2002) afirma que o manejo correto da floresta reduz em $30 \%$ os desperdícios e danos na estrutura florestal, aumentando a rentabilidade em $35 \%$ a mais que a exploração convencional, atendendo a demanda de mercado com o uso menor desta área não planejada.

O manejo florestal de espécies nativas na Amazônia brasileira está baseado na aplicação de sistemas silviculturais corretos, na extração de um número mínimo de espécies por hectare e de técnicas de exploração florestal de impacto reduzido ou nos desbastes seletivos (JARDIM et al., 1996). A extração de madeira em florestas tropicais é uma atividade que causa grandes impactos ao ecossistema e só através do planejamento adequado e de boas práticas de manejo, 'e possível amenizar os impactos e conseguir uma produção mais sustentável, tanto do ponto de vista ambiental como econômico (SILVA et al., 2001).

A utilização de técnicas de exploração de impacto reduzido tem mostrado uma redução nos impactos na época da extração madeireira, o que não necessariamente melhora as taxas de crescimento de muitas espécies comerciais e/ou nem assegura o retorno dos volumes explorados para o próximo ciclo de corte (PEÑA-CLAROS et al., 2008).

Estudo feito como cortes de liberação de copa, corte de cipós e anelamento de competidoras em árvores comerciais de florestas tropicais tem mostrado crescimento significativo em suas taxas de 
crescimento (WADSWORTH et al., 2006). Os tratamentos silviculturais podem aumentar consideravelmente o crescimento e um alto valor das árvores no mercado comercial. Pesquisas mostram que esse crescimento pode ser duplicado em relação a áreas exploradas e não tratadas ou até quadruplicado em relação a uma floresta não explorada (HOLMES et al., 2002).

Em florestas naturais as espécies competem pela sobrevivência onde as mais abundantes e de baixo valor comercial dominam a área, reduzindo o crescimento das espécies comerciais. A remoção de indivíduos competidores cuja copa esteja dificultando a entrada de luz e a redução da área basal de espécies não desejáveis faz com que a floresta acelere as taxas de crescimento, proporcionando melhores indivíduos para a próxima colheita (AZEVEDO et al., 2012).

Apesar da necessidade de se aplicar os tratamentos silviculturais para melhorar a regeneração natural, manter a qualidade da produção, fazer a seleção da composição florística e melhorar o crescimento das árvores para definir a volumetria, essas técnicas silviculturas não são aplicadas em escala operacional e nem sequer são contemplados dentro do planejamento das operações florestais (FREDERICKSEN et al., 2003; DAUBER et al., 2005; KELLER et al., 2007). Motivado pela falta de conhecimento sobre as técnicas de manejo da equipe, dificuldades de adquirir mudas de espécies florestais, pelos altos custos dessa operação, que demanda trabalhadores capacitados, e da pressão do mercado consumidor de madeira por um material de excelente qualidade levam as empresas florestais a deixarem para um segundo momento essa etapa dos tratamentos silviculturais (SABOGAL et al., 2006).

Diante disso a hipótese técnica de exploração de impacto reduzido e uso de tratamentos silviculturais estimulam o crescimento volumétrico e favorecem o aparecimento de novas espécies arbóreas. Sendo assim, o objetivo do trabalho é analisar o efeito dos tratamentos silviculturais sobre a dinâmica volumétrica de espécies arbóreas comerciais e não comerciais após a exploração florestal em uma área experimental da Embrapa Amazônia Oriental no município de Vitória do Jari, Amapá.

\section{MATERIAIS E MÉTODOS}

\section{Área de Estudo}

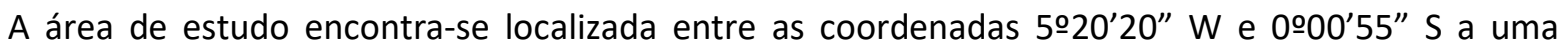
altitude de aproximadamente 150 m, numa localidade chamada Morro do Felipe no município de Vitória do Jari/AP (FIGURA 1). O clima nessa região é do tipo Ami pela classificação de Köppen. A precipitação média anual alcança $2.234 \mathrm{~mm}$ com um período chuvoso de dezembro a maio. Ocorre uma estação seca de três meses que se inicia em junho e que se caracteriza por uma precipitação mensal inferior a $8 \%$ do volume anual de chuva (AZEVEDO et al., 2008). 

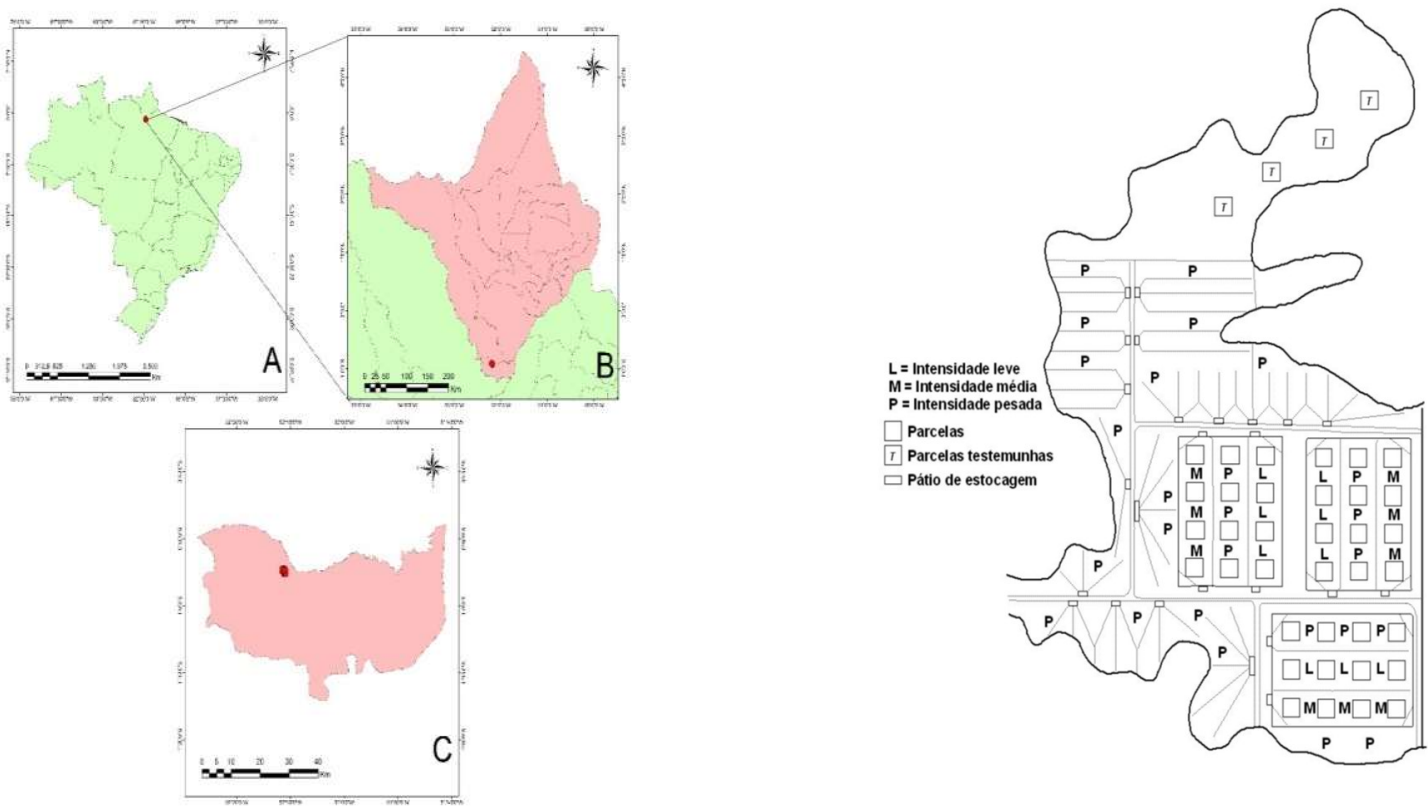

Figura 1: Croqui experimental das parcelas de monitoramento permanentes, distribuídas em intensidade de exploração leve (L), média (M) e pesada (P) da Jari, localidade Morro do Felipe (C), Vitória do Jari, (B) Amapá, Brasil (A). Fonte: Azevedo (2012).

A temperatura média anual é de 25,80 C, com a amplitude térmica variando mais ou menos 20 ㅇ C entre o máximo e o mínimo valor mensal. Na Jari a vegetação é do tipo Floresta Ombrófila Densa. Os solos são do tipo Latossolo Amarelo Distrófico com textura argilosa pesada (AZEVEDO et al., 2008).

\section{Delineamento experimental}

O experimento foi iniciado em 1983, com a realização do inventário pré-exploratório considerando todas as árvores com Diâmetro Altura do Peito (DAP) $\geq 50 \mathrm{~cm}$. Em 1985 foi realizada a exploração florestal na área de floresta primária retirando $15 \%, 25 \%$ e $35 \%$ do volume total das árvores com DAP $\geq 50 \mathrm{~cm}$, correspondendo, aproximadamente, a $25 \mathrm{~m}^{3} \mathrm{ha}, 40 \mathrm{~m}^{3}$ ha e $60 \mathrm{~m}^{3} \mathrm{ha}$, respectivamente. Foram exploradas árvores com $\mathrm{DAP} \geq 60 \mathrm{~cm}$ de 26 espécies de valor comercial na região. $O$ tratamento silvicultural foi realizado em 1994 aplicando-se dois tipos de desbaste: desbaste sistemático, com duas intensidades de redução da área basal original (30\% e 50\%), e o desbaste seletivo.

O delineamento experimental das áreas estudadas foi o bloco ao acaso com três repetições. As alternativas de manejo testadas foram combinações de intensidades de exploração com intensidades de desbastes. As intensidades de exploração (15\% - intensidade leve, $25 \%$ - intensidade média e 35\% intensidade pesada) foram representadas por porcentagens do volume extraído em relação ao volume total da floresta a partir do diâmetro à altura do peito (DAP) de $60 \mathrm{~cm}$. Elas foram combinadas com quatro tipos de intensidades de desbastes, o desbaste sistemático e o desbaste seletivo nas intensidades de $0 \%, 30 \%, 50 \%$ e $70 \%$ de redução da área basal original.

\section{Coleta de dados}

Os procedimentos para coleta e registro dos dados nas parcelas permanentes foram àqueles 
estabelecidos nas diretrizes propostas por Silva et al. (2005). Foram realizadas oito medições nos anos de 1984, 1986, 1988, 1990, 1994, 1996, 2004 e 2011. O trecho da floresta foi selecionado através de parcelas ao longo das linhas de amostragem. Selecionaram-se, exclusivamente, espécies arbóreas em centímetro para depois ser transformado em Diâmetro à Altura do Peito (DAP) $\geq 20 \mathrm{~cm}$. Os indivíduos foram amostrados e identificados em campo com auxílio de identificador botânico da Embrapa Amazônia Oriental. Não houve inclusão de palmeiras nesse trabalho, assim como de regeneração natural, uma vez que os trabalhos serão dirigidos a uma exploração florestal. Somente indivíduos com porte arbóreo exigido pela legislação foram considerados.

Cada parcela de 1 ha foi dividida em subparcelas de $10 \mathrm{~m} \times 10 \mathrm{~m}$. As parcelas e subparcelas foram demarcadas com piquetes, os quais foram pintados na parte superior com tinta vermelha acrílica, para diferenciá-los da vegetação e para facilitar as atividades de monitoramento. A estrutura diamétrica foi caracterizada por meio das distribuições do número de árvores, da área basal e do volume de fuste por hectare, por espécie e por classe de diâmetro.

\section{Análise de dados}

A composição florística foi analisada com base na distribuição dos indivíduos em espécies e famílias e no índice de Shannon-Weaner (BROWER et al., 1984). Foram consideradas como espécies raras ou de baixa densidade aquelas que se apresentaram com até dois indivíduos por hectare.

De modo a comparar a dinâmica do volume médio da floresta testemunha com o tratamento antes da exploração (1984) e pós-exploração 1986 (1988; 1990; 1994; 1996; e 2011). Os dados foram ajustados em matriz de modo a aplicar a análise de variância para testar a hipótese de nulidade (H0: não existência de diferença significativa entre as médias dos tratamentos). As médias das classes de volumes nas parcelas com tratamento silvicultural (TR) e parcelas testemunhas (TE) foram comparadas através do teste Tukey ao nível de $5 \%$ de probabilidade. Foi utilizado o programa ASSISTAT 5.2.

Foi comparado o volume médio do tratamento em 1984 mais a testemunha de 1984 (TR+TE) com o tratamento de 1986 (TR) e verificou-se que houve diferença significativa entre as médias dos volumes. Isso se deu através da exploração florestal aplicada no ano de 1985 provocando redução da volumetria em 6,4\% das espécies comerciais.

Seguiu essa mesma metodologia para os anos seguintes nas remedições fazendo comparação com TR-1988; comparando com o TR-1990; comparando com o TR-1994 e comparando com o TR-1996. Nos seis primeiros registros verificou-se que houve diferença significativa entre as médias desses volumes. Em 1994 houve uma nova redução da área basal com aplicação dos tratamentos silviculturais, com redução mínima do volume (TABELA 4). Depois foi realizado o teste-t bicaudal na comparação da floresta em termos de volume para o evento tratamento silvicultural (1990-1996), (1990-2004) e (1990-2011).

\section{RESULTADOS E DISCUSÃO}

Considerando HO 'Se o tratamento silvicultural for aplicado em floresta nativa, logo haverá aumento 
de volume comercial e total' a hipótese sugere que a afirmação que estamos fazendo sobre o parâmetro populacional é verdadeira. Portanto, o tratamento silvicultural aplicado nas árvores garante a continuidade da produção madeireira proporcionando novas colheitas e favorecendo o aumento do crescimento das árvores.

\section{Composição florística}

Em 27 anos de estudo foram registrados 6.304 indivíduos com DAP $\geq 20 \mathrm{~cm}$ (TABELA 6). Em 1986, um ano após a exploração, e em 1988, três anos após a exploração, foram encontrados respectivamente 166,11 e 163,09 registros de indivíduos/ha com DAP $\geq 20 \mathrm{~cm}$. Nos outros períodos o número de famílias, gêneros e espécies tiveram pouca variação em relação a 1984. A partir do vigésimo (20) ano, surgiram diferenças na composição florística com ganho de espécies e família (Tabela 6).

Ao longo de 27 anos de monitoramento na área experimental de 36 ha da Jari a intensidade de exploração associada à aplicação do tratamento silvicultural (1985 e 1994) favoreceram o ingresso de 80 novas espécies e a saída (mortalidade) de 23 espécies. As espécies foram assim distribuídas entre os anos: em 1984 tinham 340 espécies, em 1986 entraram 4 espécies (Hirtella piresii, Maprounea guianensis, Palicourea guianensis, Protium altsonii) e saíram 5 espécies (Aspidosperma rigidum, Cecropia sciadophylla, Ferdinandusa paraensis, Hymenolobium petraeum, Pterocarpus sp.); em 1988 entraram 4 espécies (Bellucia dichotoma, Ocotea sprucei, Pourouma sp., Pouteria procera) e saiu a Cecropia palmata; em 1990 entraram 9 espécies, sendo 3 identificadas a nível de família (Aspidosperma oblongum, Byrsonima stipulacea, Couratari oblongifolia, Margaritaria nobilis, Meliaceae, Moraceae, Pourouma guianensis, Salicaceae, Virola caducifolia) e saíram 4 espécies (Cheiloclinium cognatum, Micropholis mensalis, Rollinia fendleri, Sacoglottis guianensis).

Tabela 1: Número de indivíduos (N) por hectare com DAP $\geq 20 \mathrm{~cm}$, famílias (F), gêneros (G) e espécie (E) ocorrentes em uma amostra de 36 ha de floresta nativa na Jari, AP.

\begin{tabular}{c|cccccccc}
\hline & 1984 & 1986 & 1988 & 1990 & 1994 & 1996 & 2004 & 2011 \\
\hline $\mathrm{N}$ & 6319 & 5980 & 5871 & 5798 & 6096 & 5866 & 6399 & 6304 \\
$\mathrm{~F}$ & 54 & 55 & 54 & 55 & 55 & 54 & 58 & 60 \\
$\mathrm{G}$ & 166 & 166 & 167 & 166 & 170 & 170 & 175 & 176 \\
$\mathrm{E}$ & 340 & 341 & 344 & 351 & 365 & 364 & 401 & 420 \\
\hline
\end{tabular}

Em 1994 ingressaram 16 espécies (Abarema campestris, Abarema jupunba, Caryocar glabrum, Copaifera multijuga, Guarea kunthiana, Inga edulis, Pachira aquatica, Patinoa paraensis, Protium pallidum, Protium sp., Pseudobombax munguba, Swartzia grandifolia, Tachigali chrysophylla, Tachigali paraensis, Vantanea guianensis, Vatairea paraensis) e saíram duas espécies (Zanthoxylum fagara, Zanthoxylum sp.); em 1996 entraram 7 espécies (Casearia pitumba, uma espécies identificada a nível de família - Flacoutiaceae, Guarea sp., Heisteria sp., Leptolobium nitens, Myrcia clusiifolia, Qualea coerulea) e saíram 5 espécies (Dalbergia spruceana, Iryanthera sagotiana, Macrolobium acaciifolium, Siparuna sp. e Fabaceae - uma espécies identificada a nível de família).

Atualmente, a legislação ambiental brasileira trabalha a questão do manejo florestal de uso múltiplo, 
com a retirada dos produtos e subprodutos da floresta de uma forma sustentável ${ }^{1}$. As empresas madeireiras entram na floresta em busca de espécies valiosas e seu corte faz com que diminua a sua abundância. Nas áreas próximas de rodovias e o baixo custo de transporte permite a exploração de várias espécies comerciais. Hoje a alternativa mais viável é a procura por novas espécies, que no passado eram tidas como potenciais, e agora possuem comércio nacional.

Em 2004 entraram 41 espécies (Annona sericea, Aspidosperma sandwithianum, Dacryodes nitens, Diospyros duckei, Diospyros guianensis, Duroia macrophylla, Dussia discolor, Eriotheca globosa, Eugenia moschata, Guarea grandifolia, Guarea pubescens, Guatteria longicuspis, Homalium racemosum, uma espécie identificada como Humiriaceae, Inga macrophylla, Inga micradenia, Inga negrensis, Inga striata, Inga tarapotensis, Lacistema aggregatum, Miconia mirabilis, Miconia sp., Mouriria sp., Neea sp., Ocotea longifolia, Ormosia coccinea, Ormosia discolor, Parkia reticulata, Pterocarpus rohrii, Sagotia racemosa, Schefflera morototoni, Sterculia pruriens, Sterculia sp., Tachigali guianensis, Tachigali melinonii, Tapura amazonica, Vismia sp., Vochysia sp., Xylopia benthamii, Xylopia sp., Zygia latifolia) e saíram 8 (Aniba rosaeodora, Buchenavia parvifolia, Cecropia sp., Cordia sp., Couepia robusta, Diplotropis racemosa, Poraqueiba guianensis, Virola sebifera).

Em 2011 entraram 28 espécies (Aspidosperma megalocarpum, Bellucia grossularioides, Bellucia sp., Brosimum alicastrum, Byrsonima aerugo, Casearia sp., Casearia sylvestris, Chrysophyllum sp., Cordia bicolor, Eschweilera parviflora, Guatteria punctata, Guatteria schomburgkiana, Inga gracilifolia, Inga thibaudiana, Joannesia heveoides, Licania sp., Mezilaurus itauba, Naucleopsis caloneura, Ormosia sp., Protium krukovii, Prunus sp., Rhamnaceae, Rinorea sp., Sapindaceae, Sterculia apeibophylla, Tachigali paniculata, Virola multinervia, Vismia sp.) e saíram 17 espécies (Couepia guianensis, Couepia robusta, Dussia discolor, uma espécie identificada como Salicaceae Guarea pubescens, Inga macrophylla, Mouriria sp., Neea oppositifolia, Onychopetalum amazonicum, Ormosia paraensis, Pseudobombax munguba, Quararibea guianensis, Recordoxylon stenopetalum).

BRAZ et al. (2014) citam que o pequeno número de espécies florestais comerciais somados a heterogeneidade da floresta tropical amazônica fazem com que o rendimento de madeira por hectare seja baixo e que apenas uma parte (10\%) desse volume de madeira da região Amazônica cheguem às serrarias, $49 \%$ são usados como lenha e o restante é descartado como resíduo florestal, e, portanto, existindo a preocupação das empresas madeireiras de selecionar a entrada de novas espécies para o mercado consumidor.

\section{Análise estatística de comparação}

Através do resultado da comparação do volume médio total do TR em 1984 mais a TE de 1984 com o TR de 1986, verificou-se que houve diferença significativa entre as médias dos volumes ( $\mathrm{F}=10,1977$; P <

\footnotetext{
${ }^{1}$ Dec. $N^{\circ} 2.788$, de 28 de setembro de 1998, Art. $1^{\circ}$ conceito de manejo florestal de uso múltiplo: "a administração da floresta para a obtenção de benefícios econômicos, sociais e ambientais, respeitando-se os mecanismos de sustentação do ecossistema objeto do manejo, e considerando-se, cumulativa ou alternativamente, a utilização de múltiplas espécies madeireiras, de múltiplos produtos e subprodutos não madeireiros, bem como a utilização de outros bens e serviços de natureza florestal".
} 
0,0001), através da exploração florestal aplicada no ano de 1985, provocando redução da volumetria em 6,4\% das espécies comerciais (TABELA 7). A comparação com TR-1988 verificou-se que houve diferença significativa entre as médias dos volumes $(F=13,5922 ; \mathrm{P}<0,0001)$, reduziu em $7,4 \%$ o volume médio comercial; comparando com o TR-1990 ( $F=17,0163$; $P<0,0001)$, ocorreu a maior perda em volume, reduzindo para 8,6\%; comparando com o TR-1994 ( $F=8,4798 ; \mathrm{P}<0,0004)$ registrou-se a menor diminuição em volume, somente $4,1 \%$ e comparando com o TR-1996 ( $F=12,9083 ; P<0,0001)$ registrou-se $7,7 \%$ na perda desse volume médio total. Nos seis primeiros registros verificou-se que houve diferença significativa entre as médias desses volumes.

Tabela 2: Resultados do teste de Tukey ao nível de 5\% de probabilidade para as médias de volume de uma amostra de 40 ha de floresta nativa, considerando árvores com DAP $\geq 20 \mathrm{~cm}$ da Jari, AP.

\begin{tabular}{|c|c|c|c|}
\hline Tratamento & Testemunha & 1984 & 1986 \\
\hline Comparação I & $43,31995 \mathrm{a}$ & 39,19658 a & $36,71283 b$ \\
\hline DMS & \multicolumn{3}{|l|}{4,3793} \\
\hline CV\% & \multicolumn{3}{|l|}{8,59} \\
\hline $\mathrm{F}$ & \multicolumn{3}{|l|}{$10,1977^{* *}$} \\
\hline $\mathrm{P}$ & \multicolumn{3}{|l|}{$<0,0001$} \\
\hline Tratamento & Testemunha & 1984 & 1988 \\
\hline Comparação II & 43,31995 a & $39,19658 a$ & $36,21695 b$ \\
\hline DMS & \multicolumn{3}{|l|}{4,2721} \\
\hline CV\% & \multicolumn{3}{|l|}{8,43} \\
\hline $\mathrm{F}$ & \multicolumn{3}{|l|}{$13,5922 * *$} \\
\hline$P$ & \multicolumn{3}{|l|}{$<0,0001$} \\
\hline Tratamento & Testemunha & 1984 & 1990 \\
\hline Comparação III & $43.31995 \mathrm{a}$ & $39.19658 a$ & $35.82985 b$ \\
\hline DMS & \multicolumn{3}{|l|}{4,1623} \\
\hline CV\% & \multicolumn{3}{|l|}{8,26} \\
\hline $\mathrm{F}$ & \multicolumn{3}{|l|}{$17,0163 * *$} \\
\hline$P$ & \multicolumn{3}{|l|}{$<0,0001$} \\
\hline Tratamento & Testemunha & 1984 & 1994 \\
\hline Comparação IV & $43,31995 \mathrm{a}$ & $39,19658 b$ & $37,59115 b$ \\
\hline DMS & \multicolumn{3}{|l|}{3,8073} \\
\hline CV\% & \multicolumn{3}{|l|}{7,39} \\
\hline $\mathrm{F}$ & \multicolumn{3}{|l|}{$8,4798 * *$} \\
\hline $\mathrm{P}$ & \multicolumn{3}{|l|}{0,0004} \\
\hline Tratamento & Testemunha & 1984 & 1996 \\
\hline Comparação V & $43.31995 \mathrm{a}$ & 39.19658 a & $36.16934 b$ \\
\hline DMS & \multicolumn{3}{|l|}{4.4319} \\
\hline CV\% & \multicolumn{3}{|l|}{8.75} \\
\hline $\mathrm{F}$ & \multicolumn{3}{|l|}{$12.9083^{* *}$} \\
\hline$P$ & \multicolumn{3}{|l|}{$<0,0001$} \\
\hline Tratamento & Testemunha & 1984 & 2004 \\
\hline Comparação V I & $43.31995 \mathrm{a}$ & $39.19658 \mathrm{a}$ & $39.11323 \mathrm{a}$ \\
\hline DMS & \multicolumn{3}{|l|}{4,9226} \\
\hline CV\% & \multicolumn{3}{|l|}{9,38} \\
\hline $\mathrm{F}$ & \multicolumn{3}{|l|}{$2,4155 \mathrm{~ns}$} \\
\hline$P$ & \multicolumn{3}{|l|}{0,0964} \\
\hline Tratamento & Testemunha & 1984 & 2011 \\
\hline Comparação VII & 43,31995 a & 39,19658 a & 39,99598 a \\
\hline DMS & 5,1352 & & \\
\hline CV\% & 9,68 & & \\
\hline $\mathrm{F}$ & $2,1579 \mathrm{~ns}$ & & \\
\hline $\mathrm{P}$ & 0,1229 & & \\
\hline
\end{tabular}

** significativo ao nível de $1 \%$ de probabilidade $(p<0,01)$

* significativo ao nível de $5 \%$ de probabilidade $(0,01 \leq p<0,05)$

ns não significativo ( $p \geq 0,05)$

As médias seguidas pela mesma letra não diferem estatisticamente entre si. 
Em 1994 ocorreu uma nova redução da área basal com aplicação dos tratamentos silviculturais, mesmo assim, a redução do volume foi mínima (TABELA 2). Em 20 anos de estudo verificou-se que não houve diferença significativa entre as médias, fazendo a comparação com TR-2004 ( $F=2,4155 ; P<0,0964)$. Observou-se que o volume neste ano aproximou-se do volume de 1984 e fazendo a comparação com TR$2011(\mathrm{~F}=2,1579 ; \mathrm{P}<0,1229)$ o volume aumentou em 1,2\% $\left(39,86219 \mathrm{~m}^{3} . \mathrm{ha}^{-1}\right)$ ultrapassando o volume inicial de $39,19632 \mathrm{~m}^{3} \mathrm{ha}^{-1}$. Os estudos de Inventário Florestal devem sempre ser balizados por parâmetros estatísticos que definem a precisão requerida para os resultados obtidos. Estes parâmetros estão condicionados por indicadores estatísticos tais como variância, desvio padrão, coeficiente de variação, etc. .

Silva et al. (2014), estudando equações de volume em Paragominas/PA, levaram em consideração a significância da estatística $t$, de Student, associada às estimativas dos parâmetros. Essa estatística foi fundamental, pois um valor não diferente de zero indica que a variável não é relevante para explicar as variações do volume e citam, também, que valores altos apresentados pela estatística R2 e F e estatísticas $t$ não significantes são sintomas de elevado grau de multicolinearidade nas regressões múltiplas, neste caso as variáveis são altamente correlacionadas, indicando a existência forte de correlação entre duas (ou mais) variáveis independentes.

Observa-se um período de decréscimo lento no volume médio nas medições de 1986, 1988 e 1990. A partir daí, ocorre um aumento desse volume em 1994 e diminui em 1996, depois disso, ocorrem dois crescimentos, um em 2004 aproximando-se do volume inicial e outro em 2011, que correspondeu ao maior crescimento em volume nos 27 anos de monitoramento.

Nota-se que, além das diferenças de crescimento entre os anos, observam-se diferenças de crescimento entre classes diamétricas, independentes dos períodos de crescimento. Apesar dos resultados estarem baseados em amostragem pequena é um indicativo importante de se adotarem técnicas de manejo distintas entre as espécies ou grupos de espécies identificando e favorecendo as classes diamétricas mais produtivas de todas as espécies (BRAZ, 2010).

O coeficiente de variação abaixo de $15 \%$ apresenta baixa variabilidade, comprovam que as árvores cresceram nas mesmas proporções, sendo o crescimento em volume de forma homogênea. Nos primeiros períodos, onde os resultados foram significativos, não deu tempo de recuperar o volume na floresta, entretanto, 20 anos depois, a floresta se equivaleu à floresta inicial e com as mesmas características, estatisticamente, voltou ao seu volume inicial. Uma floresta pós-exploração que ocorre tratamento silvicultural após 10 anos, em 20 anos, estará equivalente ao ano anterior à exploração (1984).

O coeficiente de variação (CV) dar uma ideia de variação relativa da população permitindo a comparação de duas ou mais populações diferentes independentes das unidades de medida. Mesmo se tratando de populações diferentes podemos concluir com base nos CVs, que a comparação IV é a mais homogênea e a comparação VII é a mais heterogênea. Isto é possível porque o CV e uma medida relativa que independente da unidade de medida utilizada. $\mathrm{O}$ incremento anual em diâmetro em árvores adultas tende a estabilizar ao longo do tempo, antes de atingir o declínio natural, sendo que cada indivíduo ou espécie reflete suas próximas condições e limitações de crescimento. 
Oscilações anuais de maior crescimento nas árvores são esperadas sem condições mais favoráveis. No entanto, quando observamos o crescimento médio das espécies tolerantes a luz, constatamos que o crescimento dessas plantas está respondendo diretamente ao ambiente, seja por variações nas condições climáticas ao longo do tempo ou por interferências antrópicas. Alguns estudos já apresentaram a relação de crescimento de árvores de espécies tropicais com fenômenos climáticos (BARICHIVICH et al., 2009; SCHONGART et al., 2006).

O cenário dinâmico do volume das árvores com DAP $\geq 20 \mathrm{~cm}$ monitorado a partir de 1984 acumulava 39,1963 $\mathrm{m}^{3}$ por hectare. Um ano após a exploração florestal, em 1986, houve um decréscimo de 2,51 $\mathrm{m}^{3}$ na volumetria. Esse cenário permaneceu decrescente até 1990, diminuindo para 3,37 $\mathrm{m}^{3}$. Na passagem do ano de 1984para o ano de 1990, ou seja, seis anos de diferença, houve perda através da exploração florestal de 26 espécies. Em 1994, próximo de completar 10 anos de monitoramento, obteve-se uma elevação na volumetria passando para $37,59 \mathrm{~m}^{3}$.

Na segunda década de monitoramento, de 1994 até 2004, houve mudança na volumetria em 1996, diminuindo o volume para $36,16 \mathrm{~m}^{3}$. Esse fato se deu através da retirada de área basal com a aplicação dos tratamentos silviculturais. Em 2004, 20 anos de monitoramento, estatisticamente a floresta se recuperou chegando bem próximo do volume inicial $\left(39,11 \mathrm{~m}^{3}\right)$ de 1984. Logo após em 2011, ou seja, 27 anos após a primeira exploração, a volumetria ultrapassou em $0,75 \mathrm{~m}^{3}$ o volume inicial, passando para $39,8621 \mathrm{~m}^{3}$ por hectare (FIGURA 2).

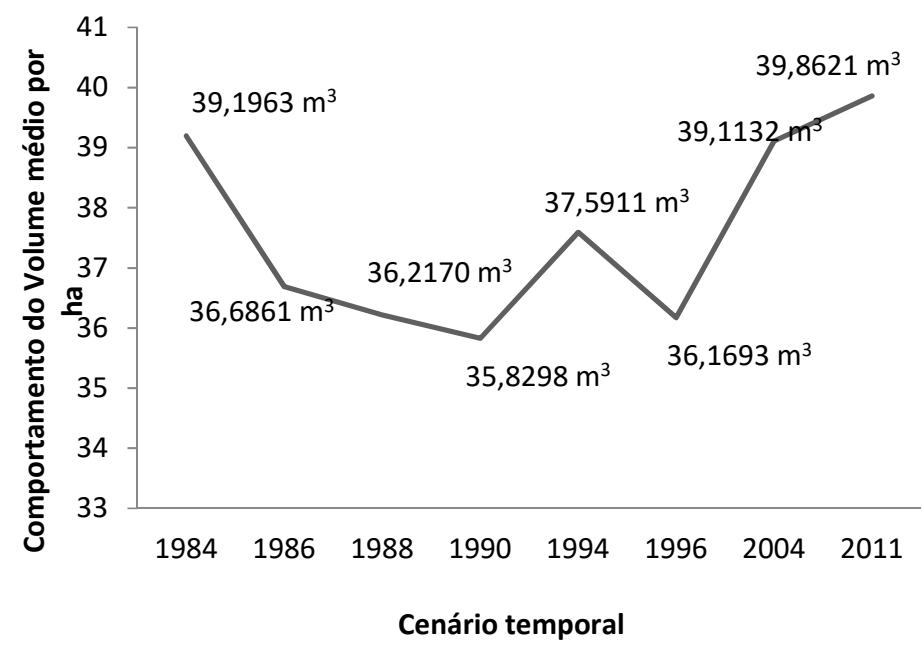

Figura 2: Incremento Médio do volume em $\mathrm{m}^{3}$ ha-1 para um trecho 36 ha de floresta nativa da Companhia Florestal Monte Dourado (Jari), Vitória do Jari, Estado do Amapá, Brasil.

O novo Código Florestal (Lei 12.651, de 25 de maio de 2012) de acordo com o art. 31.o , parágrafo § 1., inciso $\mathrm{Vl}$, que a floresta tem que ter um ciclo de corte compatível com o tempo de restabelecimento do volume de produto extraído da floresta e preconiza que, para existir sustentabilidade em um projeto de manejo florestal na Amazônia brasileira, a área que sofreu a exploração florestal recupere a volumetria inicial, após um ciclo de corte de no mínimo de 30 anos.

Considerando-se o teste-t bicaudal na comparação da floresta em termos de volume para o evento exploração (1984-2011), obteve-se nível descritivo $(P=0,212333)$, sendo este maior que $(\alpha=0,05)$, conclui- 
se, em não rejeitar a hipótese nula $\left(\mathrm{HO}: \mu \mathrm{i}_{1984}=\mu \mathrm{i}_{2011}\right)$ e assim as médias entre os períodos não apresentarem diferença estatisticamente significativo.

Com base na TABELA 3 e comparando os períodos antes da exploração (1984) com os períodos de pós-exploração $(1986,1988,1990,1996,2004$ e 2011) via teste-t bilateral, os resultados sugerem, com nível descritivo para os períodos avaliados. Conclui-se em rejeitar a hipótese nula (HO: $\mu \mathrm{i}_{1984}=\mu \mathrm{i}_{1986}, \mu \mathrm{i}_{1984}=\mu \mathrm{i}_{1988}$, $\left.\mu \mathrm{i}_{1984}=\mu \mathrm{i}_{1990}, \mu \mathrm{i}_{1984}=\mu \mathrm{i}_{1994}, \mu \mathrm{i}_{1984}=\mu \mathrm{i}_{1996}, \mu \mathrm{i}_{1984}=\mu \mathrm{i}_{2004} \mathrm{e} \mu \mathrm{i}_{1984}=\mu \mathrm{i}_{2011}\right)$ logo as médias em volume para os períodos estudado podem ser considerado diferente estatisticamente.

Tabela 3: Comparação entre dois períodos através do Teste-t para duas amostras em par para médias dos volumes após a exploração florestal, considerando árvores com DAP $\geq 20 \mathrm{~cm}$ da Jari, AP.

\begin{tabular}{|c|c|c|}
\hline 1984-1986 & 36,14325 & 32,36376 \\
\hline Média & 39,28355 & 36,80966 \\
\hline Variância & 8,824205 & 13,21957 \\
\hline Observações & 35 & 35 \\
\hline Correlação de Pearson & 0,895544 & \\
\hline Hipótese da diferença de média & 0 & \\
\hline gl & 34 & \\
\hline Stat t & 8,908632 & \\
\hline $\mathrm{P}(\mathrm{T}<=\mathrm{t})$ uni-caudal & $1,03 \mathrm{E}-10$ & \\
\hline t crítico uni-caudal & 1,690924 & \\
\hline $\mathrm{P}(\mathrm{T}<=\mathrm{t})$ bi-caudal & $2,06 \mathrm{E}-10$ & \\
\hline t crítico bi-caudal & 2,032245 & \\
\hline 1984-1988 & 36,14325 & 33,07223 \\
\hline Média & 39,28355 & 36,30692 \\
\hline Variância & 8,824205 & 12,49702 \\
\hline Observações & 35 & 35 \\
\hline Correlação de Pearson & 0,887836 & \\
\hline Hipótese da diferença de média & 0 & \\
\hline gl & 34 & \\
\hline Stat t & 10,76816 & \\
\hline $\mathrm{P}(\mathrm{T} \leq \mathrm{t})$ uni-caudal & $8,48 \mathrm{E}-13$ & \\
\hline t crítico uni-caudal & 1,690924 & \\
\hline $\mathrm{P}(\mathrm{T} \leq \mathrm{t})$ bi-caudal & $1,7 \mathrm{E}-12$ & \\
\hline t crítico bi-caudal & 2,032245 & \\
\hline $1984-1990$ & 36,14325 & 32,70605 \\
\hline Média & 39,28355 & 35,91913 \\
\hline Variância & 8,824205 & 11,38172 \\
\hline Observações & 35 & 35 \\
\hline Correlação de Pearson & 0,813577 & \\
\hline Hipótese da diferença de média & 0 & \\
\hline gl & 34 & \\
\hline Stat t & 10,08007 & \\
\hline $\mathrm{P}(\mathrm{T} \leq \mathrm{t})$ uni-caudal & $4,75 \mathrm{E}-12$ & \\
\hline t crítico uni-caudal & 1,690924 & \\
\hline $\mathrm{P}(\mathrm{T} \leq \mathrm{t})$ bi-caudal & $9,51 E-12$ & \\
\hline t crítico bi-caudal & 2,032245 & \\
\hline 1984-1994 & 36,14325 & 34,55033 \\
\hline Média & 39,28355 & 37,67803 \\
\hline Variância & 8,824205 & 7,97934 \\
\hline Observações & 35 & 35 \\
\hline Correlação de Pearson & 0,743605 & \\
\hline Hipótese da diferença de média & 0 & \\
\hline gl & 34 & \\
\hline Stat t & 4,567709 & \\
\hline $\mathrm{P}(\mathrm{T} \leq \mathrm{t})$ uni-caudal & $3,1 \mathrm{E}-05$ & \\
\hline t crítico uni-caudal & 1,690924 & \\
\hline $\mathrm{P}(\mathrm{T} \leq \mathrm{t})$ bi-caudal & $6,2 \mathrm{E}-05$ & \\
\hline t crítico bi-caudal & 2,032245 & \\
\hline 1984-1996 & 36,14325 & 28,35722 \\
\hline
\end{tabular}




\begin{tabular}{|c|c|c|}
\hline Média & 39,28355 & 36,39254 \\
\hline Variância & 8,824205 & 12,63076 \\
\hline Observações & 35 & 35 \\
\hline Correlação de Pearson & 0,572258 & \\
\hline Hipótese da diferença de média & 0 & \\
\hline $\mathrm{gl}$ & 34 & \\
\hline Stat t & 5,586847 & \\
\hline $\mathrm{P}(\mathrm{T} \leq \mathrm{t})$ uni-caudal & $1,48 \mathrm{E}-06$ & \\
\hline t crítico uni-caudal & 1,690924 & \\
\hline $\mathrm{P}(\mathrm{T} \leq \mathrm{t})$ bi-caudal & $2,97 \mathrm{E}-06$ & \\
\hline t crítico bi-caudal & 2,032245 & \\
\hline 1984-2004 & 36,14325 & 26,99193 \\
\hline Média & 39,28355 & 39,45955 \\
\hline Variância & 8,824205 & 15,57099 \\
\hline Observações & 35 & 35 \\
\hline Correlação de Pearson & 0,265573 & \\
\hline Hipótese da diferença de média & 0 & \\
\hline gl & 34 & \\
\hline Stat t & $-0,24427$ & \\
\hline $\mathrm{P}(\mathrm{T} \leq \mathrm{t})$ uni-caudal & 0,404243 & \\
\hline t crítico uni-caudal & 1,690924 & \\
\hline $\mathrm{P}(\mathrm{T} \leq \mathrm{t})$ bi-caudal & 0,808486 & \\
\hline t crítico bi-caudal & 2,032245 & \\
\hline $1984-2011$ & 36,14325 & 31,24133 \\
\hline Média & 39,28355 & 40,24354 \\
\hline Variância & 8,824205 & 20,28935 \\
\hline Observações & 35 & 35 \\
\hline Correlação de Pearson & 0,341865 & \\
\hline Hipótese da diferença de média & 0 & \\
\hline gl & 34 & \\
\hline Stat t & $-1,27107$ & \\
\hline $\mathrm{P}(\mathrm{T} \leq \mathrm{t})$ uni-caudal & 0,106166 & \\
\hline t crítico uni-caudal & 1,690924 & \\
\hline $\mathrm{P}(\mathrm{T} \leq \mathrm{t})$ bi-caudal & 0,212333 & \\
\hline t crítico bi-caudal & 2,032245 & \\
\hline
\end{tabular}

Considerando-se o teste-t bicaudal na comparação da floresta em termos de volume para o evento tratamento silvicultural (1990-1996) obteve-se nível descritivo $(P=0,337)$, sendo este maior que $(\alpha=0,05)$, conclui-se, em não rejeitar a hipótese nula $\left(\mathrm{HO}: \mu \mathrm{i}_{1990}=\mu \mathrm{i}_{1996}\right)$ e assim as médias entre os períodos não apresentarem diferença estatisticamente significativo (TABELA 4).

Com base na tabela 4 comparando os períodos (1990-2004) e (1990-2011), via teste-t bilateral, os resultados sugerem, com nível descritivo $(P=0,0000236>\alpha=0,05 ; P=0,00000983>\alpha=0,05$, respectivamente). Conclui-se em rejeitar a hipótese nula ( $\left.\mathrm{HO}: \mu \mathrm{i}_{1990}=\mu \mathrm{i}_{2004} \mathrm{e} \mu \mathrm{i}_{1990}=\mu \mathrm{i}_{2011}\right)$ logo as medias em volume para os períodos estudados podem ser considerados diferentes estatisticamente.

Tabela 4: Comparação entre dois períodos através do Teste-t para duas amostras em par para médias dos volumes após o tratamento silvicultural.

\begin{tabular}{|l|l|l|}
\hline $\mathbf{1 9 9 0}-1996$ & $\mathbf{3 2 , 7 0 6 0 5}$ & $\mathbf{2 8 , 3 5 7 2 2}$ \\
\hline Média & 35,91913 & 36,39254 \\
\hline Variância & 11,38172 & 12,63076 \\
\hline Observações & 35 & 35 \\
\hline Correlação de Pearson & 0,65681 & \\
\hline Hipótese da diferença de média & 0 & \\
\hline gl & 34 & \\
\hline Stat t & $-0,97437$ & \\
\hline $\mathrm{P}(\mathrm{T} \leq \mathrm{t})$ uni-caudal & 0,168376 & \\
\hline $\mathrm{t}$ crítico uni-caudal & 1,690924 & \\
\hline
\end{tabular}




\begin{tabular}{|l|l|l|}
\hline $\mathrm{P}(\mathrm{T} \leq \mathrm{t})$ bi-caudal & 0,336753 & \\
\hline $\mathrm{t}$ crítico bi-caudal & 2,032245 & \\
\hline $\mathbf{1 9 9 0}-\mathbf{2 0 0 4}$ & $\mathbf{3 2 , 7 0 6 0 5}$ & $\mathbf{2 6 , 9 9 1 9 3}$ \\
\hline Média & 35,91913 & 39,45955 \\
\hline Variância & 11,38172 & 15,57099 \\
\hline Observações & 35 & 35 \\
\hline Correlação de Pearson & 0,32408 & \\
\hline Hipótese da diferença de média & 0 & \\
\hline $\mathrm{g} \mathrm{Stat} \mathrm{t}$ & 34 & \\
\hline $\mathrm{P}(\mathrm{T} \leq \mathrm{t})$ uni-caudal & $-4,89303$ & \\
\hline $\mathrm{t}$ crítico uni-caudal & $1,18 \mathrm{E}-05$ & \\
\hline $\mathrm{P}(\mathrm{T} \leq \mathrm{t})$ bi-caudal & 1,690924 & \\
\hline $\mathrm{t}$ crítico bi-caudal & $2,36 \mathrm{E}-05$ & \\
\hline $\mathbf{1 9 9 0}-\mathbf{2 0 1 1}$ & 2,032245 & $\mathbf{3 1 , 2 4 1 3 3}$ \\
\hline Média & $\mathbf{3 2 , 7 0 6 0 5}$ & 40,24354 \\
\hline Variância & 35,91913 & 20,28935 \\
\hline Observações & 11,38172 & 35 \\
\hline Correlação de Pearson & 35 & \\
\hline Hipótese da diferença de média & 0,241507 & \\
\hline $\mathrm{g} \mathrm{g}$ & 0 & \\
\hline Stat t & 34 & \\
\hline $\mathrm{P}(\mathrm{T} \leq \mathrm{t})$ uni-caudal & $-5,18657$ & \\
\hline $\mathrm{t}$ crítico uni-caudal & $4,92 \mathrm{E}-06$ & \\
\hline $\mathrm{P}(\mathrm{T} \leq \mathrm{t})$ bi-caudal & 1,690924 & \\
\hline $\mathrm{t}$ crítico bi-caudal & $9,84 \mathrm{E}-06$ & \\
\hline & 2,032245 & \\
\hline & & \\
\hline
\end{tabular}

\section{Avaliação do volume comercial}

O volume total comercial estimado para as espécies florestais da Jari Florestal foi de $253,3389 \mathrm{~m}^{3}$. Na tabela 5, pode ser verificada a distribuição do volume comercial para uma área equivalente a 36 hectares. Fazendo a diferença de volume comercial entre 1984 e 2011 obteve-se valores positivos e negativos e se constatou que 76,92\% das espécies comerciais não recuperou seu volume inicial.

As espécies que conseguiram recuperar seu volume no período de 27 anos foram: Carapa guianensis $\left(4,47 \mathrm{~m}^{3} / \mathrm{ha}\right)$, Caryocar villosum $\left(1,2969 \mathrm{~m}^{3} / \mathrm{ha}\right)$, Dinizia excelsa $\left(0,8161 \mathrm{~m}^{3} / \mathrm{ha}\right)$, Licaria crassifolia $(4,4097$ $\left.\mathrm{m}^{3} / \mathrm{ha}\right)$, Qualea paraense $\left(2,4453 \mathrm{~m}^{3}\right)$ e Ruizterania Albiflora $\left(7,65 \mathrm{~m}^{3}\right)$. As espécies que chegaram próximas de recuperar sua volumetria inicial foram: Hymenelobium excelsum $\left(1,0912 \mathrm{~m}^{3}\right)$, Hymenelobium petraeum $\left(0,24 \mathrm{~m}^{3}\right)$, Hymenelobium sericeum $\left(2,48 \mathrm{~m}^{3}\right)$, Manilkara bidentata $\left(17,5454 \mathrm{~m}^{3}\right)$, Nectandra micranthera $\left(11,94 \mathrm{~m}^{3}\right)$, Platymiscium sp. $\left(2,08 \mathrm{~m}^{3}\right)$, Pouteria oppositifolia $\left(19,77 \mathrm{~m}^{3}\right)$, Pouteria ssp. $\left(69,02 \mathrm{~m}^{3}\right)$, Vatairea sp. $\left(4,2838 \mathrm{~m}^{3}\right)$ e Vouacapoua americana $\left(0,46 \mathrm{~m}^{3}\right)$.

Segundo Avila et al. (2015) a alta intensidade de exploração junto a redução da área basal podem provocar danos na colheita florestal que podem influenciar substancialmente sobre a comunidade de árvores com DAP $\geq 10 \mathrm{~cm}$. Uma forma de combater esse dano ambiental é determinar o nível mínimo de intervenções e evitar o desbaste forte. Isso pode melhorar a recuperação do ecossistema e a manutenção da biodiversidade em outros níveis tróficos.

Tabela 5: Lista de espécies exploradas em 1985 e seus respectivos volumes comerciais e sua variação de perda e ganho em biomassa em ( $\mathrm{m}^{3}$ ha) após 27 anos da exploração florestal da Jari, AP.

\begin{tabular}{l}
\begin{tabular}{|l|l|l|l|l|l|l|l|l|l|}
\hline Espécie comerciais & 1984 & 1986 & 1988 & 1990 & 1994 & 1996 & $\mathbf{2 0 0 4}$ & $\mathbf{2 0 1 1}$ & $\mathbf{1 9 8 4 - 2 0 1 1}$ \\
\hline
\end{tabular} \\
$\begin{array}{l}\text { Revista Ibero-Americana de Ciências Ambientais } \\
\text { v.10-n.6 - Out a Nov 2019 }\end{array}$ \\
P a g e | 62 \\
\hline
\end{tabular}




\begin{tabular}{|c|c|c|c|c|c|c|c|c|c|}
\hline Bowdichia nítida & 4,79 & 3,89 & 3,89 & 3,90 & 3,92 & 3,71 & 3,74 & 2,19 & $-2,60$ \\
\hline Carapa guianensis & 3,85 & 3,13 & 3,17 & 3,38 & 3,21 & 3,60 & 4,00 & 4,48 & 0,62 \\
\hline Caryocar villosum & 1,19 & 0,86 & 0,86 & 0,86 & 1,05 & 1,06 & 1,10 & 1,30 & 0,10 \\
\hline Combretaceae & 2,64 & 1,50 & 1,51 & 1,52 & 1,54 & 1,55 & 1,35 & 1,36 & $-1,28$ \\
\hline Dinizia excelsa & 0,78 & 0,39 & 0,39 & 0,56 & 0,57 & 0,58 & 0,80 & 0,82 & 0,04 \\
\hline Dipteryx odorata & 14,31 & 9,90 & 9,93 & 9,95 & 10,02 & 9,63 & 8,76 & 7,35 & $-6,96$ \\
\hline Goupia glabra & 54,86 & 37,16 & 36,59 & 36,37 & 35,14 & 34,80 & 35,47 & 34,43 & $-20,43$ \\
\hline Handroanthus serratifolius & 5,40 & 4,89 & 4,90 & 4,70 & 4,90 & 4,91 & 4,60 & 4,19 & $-1,21$ \\
\hline Hymenaea courbaril & 11,17 & 4,29 & 4,31 & 4,51 & 4,73 & 4,75 & 4,87 & 3,92 & $-7,25$ \\
\hline Hymenolobium excelsum & 1,88 & 1,38 & 1,38 & 1,39 & 1,41 & 1,42 & 1,09 & 1,09 & $-0,79$ \\
\hline Hymenolobium petraeum & 0,75 & 0,20 & 0,18 & 0,18 & 0,20 & 0,20 & 0,23 & 0,24 & $-0,51$ \\
\hline Hymenolobium sericeum & 2,96 & 2,30 & 2,34 & 2,54 & 2,52 & 2,55 & 2,59 & 2,49 & $-0,48$ \\
\hline Licaria crassifolia & 3,17 & 2,61 & 2,45 & 2,47 & 2,88 & 3,95 & 4,50 & 4,41 & 1,24 \\
\hline Manilkara bidentata & 19,57 & 17,26 & 17,37 & 16,49 & 17,08 & 17,17 & 16,52 & 17,55 & $-2,02$ \\
\hline Manilkara huberi & 57,20 & 40,11 & 39,44 & 39,08 & 38,65 & 39,07 & 37,60 & 36,19 & $-21,01$ \\
\hline Não identificada & 14,99 & 13,07 & 12,01 & 9,78 & 8,11 & 6,35 & 2,44 & 4,21 & $-10,78$ \\
\hline Nectandra micranthera & 12,64 & 11,06 & 10,69 & 10,41 & 11,22 & 11,39 & 13,23 & 11,94 & $-0,70$ \\
\hline Platymiscium sp. & 2,09 & 1,60 & 1,62 & 1,81 & 2,02 & 2,03 & 2,25 & 2,08 & $-0,01$ \\
\hline Pouteria oppositifolia & 23,09 & 22,08 & 22,21 & 22,16 & 21,85 & 21,62 & 21,76 & 19,78 & $-3,31$ \\
\hline Pouteria ssp. & 77,81 & 75,04 & 72,37 & 69,70 & 69,77 & 69,00 & 69,49 & 69,02 & $-8,78$ \\
\hline Qualea paraensis & 2,26 & 1,67 & 1,70 & 1,42 & 1,64 & 1,66 & 2,33 & 2,45 & 0,19 \\
\hline Ruizterania albiflora & 7,16 & 5,67 & 5,68 & 5,13 & 5,60 & 5,72 & 7,30 & 7,66 & 0,50 \\
\hline Terminalia ssp. & 3,02 & 2,17 & 2,18 & 2,20 & 2,40 & 2,42 & 2,48 & 2,86 & $-0,16$ \\
\hline Trattinnickia rhoifolia & 7,73 & 6,79 & 6,86 & 6,88 & 7,21 & 0,44 & 7,37 & 6,59 & $-1,14$ \\
\hline Vatairea sp. & 4,93 & 4,18 & 4,23 & 4,12 & 4,19 & 4,23 & 4,58 & 4,28 & $-0,65$ \\
\hline Vouacapoua americana & 0,67 & 0,41 & 0,41 & 0,42 & 0,43 & 0,44 & 0,46 & 0,47 & $-0,20$ \\
\hline Total Geral & 340,92 & 273,59 & 268,67 & 261,94 & 262,26 & 254,24 & 260,92 & 253,34 & $-87,58$ \\
\hline
\end{tabular}

As espécies que conseguiram recuperar a área basal (TABELA 6) foram: Carapa guianensis $(2,2848$ $\left.\mathrm{m}^{2} / \mathrm{ha}\right)$, Licaria crassifolia $\left(2,0563 \mathrm{~m}^{2} / \mathrm{ha}\right)$, e Platymiscium sp. $\left(1,2324 \mathrm{~m}^{2} / \mathrm{ha}\right)$. As espécies que chegaram próximas de recuperar sua volumetria inicial foram: Caryocar villosum $\left(1,7735 \mathrm{~m}^{2} / \mathrm{ha}\right)$, Handroanthus serratifolius (2,2900 $\mathrm{m}^{2} /$ ha), Hymenelobium sericeum (1,7072 $\mathrm{m}^{2} /$ ha), Manilkara bidentata $\left(15,0004 \mathrm{~m}^{2} / \mathrm{ha}\right)$, Nectandra micranthera $\left(7,6507 \mathrm{~m}^{2} / \mathrm{ha}\right)$, Qualea paraensis $\left(1,8104 \mathrm{~m}^{2} / \mathrm{ha}\right)$, Ruizterania Albiflora $(5,6270$ $\left.\mathrm{m}^{2} / \mathrm{ha}\right)$,Vatairea sp. $\left(2,2443 \mathrm{~m}^{2} / \mathrm{ha}\right)$ e Vouacapoua americana $\left(0,2233 \mathrm{~m}^{2} / \mathrm{ha}\right)$.

Tabela 6: Lista de espécies explorada e suas respectivas áreas basais ( $\mathrm{m}^{2} / \mathrm{ha}$ ) volume comercial e sua variação de perda e ganho em biomassa em $\mathrm{m}^{3}$ para o período de 27 anos de monitoramento de uma floresta nativa da Jari, AP.

\begin{tabular}{|l|l|l|l|l|l|l|l|l|l|}
\hline Espécies comerciais & $\mathbf{1 9 8 4}$ & $\mathbf{1 9 8 6}$ & $\mathbf{1 9 8 8}$ & $\mathbf{1 9 9 0}$ & $\mathbf{1 9 9 4}$ & $\mathbf{1 9 9 6}$ & $\mathbf{2 0 0 4}$ & $\mathbf{2 0 1 1}$ & $\mathbf{1 9 8 4 - 2 0 1 1}$ \\
\hline Bowdichia nitida & $\mathbf{4} 90$ & $\mathbf{3}, 53$ & $\mathbf{3}, 55$ & $\mathbf{3}, 58$ & 3,64 & 3,57 & 3,68 & 1,73 & $-3,17$ \\
\hline Carapa guianensis & 2,01 & 1,48 & 1,54 & 1,64 & 1,66 & 1,79 & 2,01 & 2,28 & 0,28 \\
\hline Caryocar villosum & 2,26 & 1,41 & 1,42 & 1,43 & 1,52 & 1,54 & 1,66 & 1,77 & $-0,49$ \\
\hline Combretaceae & 2,87 & 1,53 & 1,58 & 1,67 & 1,79 & 1,86 & 1,78 & 1,80 & $-1,07$ \\
\hline Dinizia excelsa & 5,06 & 2,36 & 2,36 & 2,39 & 2,47 & 2,48 & 2,70 & 2,72 & $-2,34$ \\
\hline Dipteryx odorata & 18,83 & 12,19 & 12,32 & 12,41 & 12,78 & 12,10 & 10,93 & 8,56 & $-10,27$ \\
\hline Goupia glabra & 65,32 & 38,30 & 38,58 & 38,52 & 37,89 & 38,04 & 39,01 & 38,54 & $-26,78$ \\
\hline Handroanthus serratifolius & 3,05 & 2,62 & 2,64 & 2,60 & 2,70 & 2,73 & 2,42 & 2,29 & $-0,76$ \\
\hline Hymenaea courbaril & 19,82 & 6,47 & 6,59 & 6,79 & 7,08 & 7,20 & 7,85 & 6,63 & $-13,19$ \\
\hline Hymenolobium excelsum & 2,61 & 2,24 & 2,27 & 2,32 & 2,43 & 2,49 & 1,24 & 1,30 & $-1,31$ \\
\hline Hymenolobium petraeum & 3,84 & 0,06 & 0,03 & 0,03 & 0,05 & 0,06 & 0,10 & 0,13 & $-3,71$ \\
\hline Hymenolobium sericeum & 2,25 & 1,33 & 1,38 & 1,46 & 1,41 & 1,47 & 1,55 & 1,71 & $-0,54$ \\
\hline Licaria crassifolia & 1,91 & 1,19 & 1,18 & 1,22 & 1,37 & 1,61 & 1,93 & 2,06 & 0,15 \\
\hline Manilkara bidentata & 15,70 & 13,84 & 14,18 & 13,84 & 14,70 & 15,04 & 14,63 & 15,00 & $-0,70$ \\
\hline Manilkara huberi & 63,07 & 33,90 & 34,15 & 34,20 & 34,58 & 35,59 & 34,18 & 33,26 & $-29,81$ \\
\hline Não identificada & 6,50 & 5,65 & 5,28 & 4,50 & 3,85 & 3,25 & 1,45 & 1,80 & $-4,70$ \\
\hline Nectandra micranthera & 8,01 & 6,87 & 6,73 & 6,40 & 6,69 & 6,69 & 7,73 & 7,65 & $-0,36$ \\
\hline Platymiscium sp. & 1,14 & 0,81 & 0,85 & 0,93 & 1,03 & 1,05 & 1,21 & 1,23 & 0,10 \\
\hline Pouteria oppositifolia & 20,01 & 19,38 & 19,75 & 20,19 & 20,56 & 20,24 & 19,55 & 17,97 & $-2,03$ \\
\hline Pouteria sp. & 41,02 & 39,82 & 39,19 & 38,12 & 38,91 & 38,40 & 36,43 & 36,72 & $-4,30$ \\
\hline Qualea paraensis & 1,96 & 1,11 & 1,19 & 0,86 & 1,00 & 1,04 & 1,49 & 1,81 & $-0,15$ \\
\hline Ruizterania albiflora & 6,08 & 3,81 & 3,83 & 2,82 & 3,18 & 3,42 & 4,65 & 5,63 & $-0,45$ \\
\hline
\end{tabular}




\begin{tabular}{|c|c|c|c|c|c|c|c|c|c|}
\hline Terminalia sp. & 3,81 & 2,60 & 2,68 & 2,77 & 2,89 & 2,99 & 3,58 & 3,44 & $-0,37$ \\
\hline Trattinnickia rhoifolia & 6,02 & 3,99 & 4,12 & 4,23 & 4,61 & 0,19 & 4,84 & 4,80 & $-1,22$ \\
\hline Vatairea sp. & 3,22 & 2,26 & 2,40 & 1,81 & 1,97 & 2,06 & 2,18 & 2,24 & $-0,98$ \\
\hline Vouacapoua americana & 0,37 & 0,12 & 0,13 & 0,14 & 0,15 & 0,16 & 0,20 & 0,22 & $-0,15$ \\
\hline Total Geral & 311,63 & 208,83 & 209,90 & 206,87 & 210,90 & 207,08 & 209,00 & 203,31 & $-108,32$ \\
\hline
\end{tabular}

As espécies que recuperaram o seu volume comercial original e as outras espécies que estão em déficit, reforçam o entendimento que o manejo florestal necessariamente deve cada vez mais aplicar o conhecimento da dinâmica florestal, principalmente, uma maior especificidade para a exploração florestal. A primeira exploração extrai-se o volume estocado, mas os próximos ciclos necessariamente devem relevar esse conhecimento para assim não levar a degradação da diversidade florestal e inclusive acelerar a extinção de tais espécies.

Thaines et al. (2010), estudando o estoque de matéria prima florestal na região da bacia do Rio Ituxi (AM), identificaram 124 espécies com DAP $\geq 50 \mathrm{~cm}$, com volume médio total de madeira de $64 \mathrm{~m}^{3} \cdot \mathrm{ha}^{-1}$, e o volume comercial estimado em $20 \mathrm{~m}^{3} \cdot \mathrm{ha}^{-1}$, aproximadamente. Foram considerados 12 espécies com mercado local e internacional, sendo as principais: Manilkara huberi, Handrohanthus spp., Cedrela odorata, Apuleia leiocarpa, Peltogyne sp., Dipteryx odorata, Ceiba pentandra, Couratari sp. e Parkia multijulga.

Pontes et al. (2010) citam que o Brasil precisa buscar alternativas para utilizar de forma racional os recursos florestais, principalmente, através de tecnologia adequada às condições regionais, que reduza o desperdício, aumente a rentabilidade, e diminua a intensidade de exploração, com melhorias na qualidade socioeconômica da população local. Precisamos conhecer e ampliar o estudo da regulação da floresta, a qual possa determinar um equilíbrio ótimo entre a intensidade de corte e a 2 a colheita que permita a floresta se recuperar de modo a garantir a produção florestal contínua.

\section{CONCLUSÕES}

As intervenções ocorridas (exploração florestal e tratamento silvicultural) na área experimental da Jari favoreceram o recrutamento de 80 espécies florestais não detectadas antes da exploração, que contribuíram com o aumento do volume da floresta, abertura provocada pela exploração, que oportunizou devido ao ciclo sucessional que essas espécies ocupassem esses nichos. 0 aumento do número de espécies e/ou o aumento da uniformidade das abundâncias, eleva a diversidade florística da área, porém, somente essa informação não é suficiente para manter a conservação dos recursos naturais. É preciso, também, criar novos mecanismos para aumentar o rendimento no processamento dos produtos florestais na indústria e diminuir o desperdício das espécies comerciais no seu processo de corte e transporte.

A floresta recuperou o volume total em menos de um ciclo de corte de 35 anos, entretanto, o baixo número de espécies comerciais exploradas, que não conseguem recuperar o volume comercial, atreladas ao baixo rendimento no seu processamento na indústria, faz com que essas espécies demorem mais tempo para serem exploradas, elevando o ciclo de corte para acima de 35 anos. Espécies valiosas no mercado, com baixa abundância e crescimento lento, podem desaparecer em um futuro próximo se não receberem uma atenção maior nos planos de manejo florestal. 
As intervenções ocorridas na área experimental da Jari favoreceram o crescimento de somente $11,58 \%$ da área basal das espécies comerciais e chegaram próximo de recuperar 46,15\% desses indivíduos. Algumas espécies comerciais não conseguem repor a área basal dentro de 27 anos de monitoramento, o que é próximo de um ciclo de corte (35 anos), portanto, devem-se estabelecer ciclos de corte adequados para as espécies ou grupos de espécies.

AGRADECIMENTOS: A Universidade Federal Rural da Amazônia - UFRA, a Embrapa Amazônia Oriental, a Capes, ao CNPQ, aos Pesquisadores, Técnicos e estudantes que de alguma maneira contribuíram para a obtenção desse trabalho.

\section{REFERÊNCIAS}

AVILA, A. L.; RUSCHEL, A. R.; DE CARVALHO, J. O. P.; MAZZEI, L.; SILVA, J. N. M.; LOPES, J. C.. ARAUJO, M. M.; DORMANN, C. F.; BAUHUS, J.. Medium-term dynamics of tree species composition in response to silvicultural intervention intensities in a tropical rain forest. Biological Conservation, v.191, p.577-586, 2015.

AZEVEDO, C. P.; SILVA, J. N. M.; SOUZA, C. R.; SANQUETTA, C. R.. Eficiência de tratamentos silviculturais por Anelamento na floresta do Jari, Amapá. Floresta, Curitiba, v.42, n.2, p.315-324, 2012.

BARICHIVICH, J.; SAUCHYN, D. J.; LARA, A.. Climate signals in high elevation tree-rings from the semiarid Andes of northcentral Chile: Responses to regional and large-scale variability. Paleogeography, Paleoclimatology, Paleoecology, v.281, p.320-330, 2009.

BRAZ, E. M.. Subsídios para o planejamento de manejo de florestas tropicais da Amazônia. Tese (Doutorado em Engenharia Florestal) - Universidade Federal de Santa Maria, Santa Maria, 2010.

BRAZ, R. L.; NUTTO, L.; BRUNSMEIER, M.; BECKER, G.; SILVA, D. A.. Resíduos da colheita florestal e do processamento da madeira na Amazônia: uma análise da cadeia produtiva. Journal of Biotechnology and Biodiversity, v.5, n.2, p.168181, 2014

BROWER, J. E.; ZAR, J. H.. Field and laboratory methods for general ecology. Dubuque: Wm. C. Brown, 1984.

DAUBER, E.; FREDERICKSEN, T. S.; PEÑA-CLAROS, M.. Sustainability of timber harvesting in Bolivian tropical forests. Forest Ecol. Manage, v.214, p.294-304. 2005

FREDERICKSEN, T. S.; PUTZ, F. E.; PATTIE, P.; PARIONA, W.; PEÑA-CLAROS, M.. Sustainable forestry in Bolivia. J. Forest, v.101, n.3740, 2003.

HOLMES, T. P.; BLATE, G. M.; ZWEEDE, J. C.; PEREIRA JUNIOR, R.; BARRETO, P.; BOLTZ, F.. Custos e benefícios financeiros da exploração de impacto reduzido em comparação à exploração florestal convencional na Amazônia Oriental. 2 ed. Belém: Fundação Floresta Tropical, 200.
JARDIM, F. C. S.; SOUZA, A. L.; BARROS, N. F.; MACHADO, C. C.; SILVA, E.; SILVA, A. F.. Técnica de abertura do dossel por anelamento de árvores na Estação Experimental de Silvicultura do INPA, Manaus/AM. B. FCAP, Belém, v.25, p.91-104, 1996.

KELLER, M.; ASNER, G. P.; BLATE, G.; MCGLOCKLIN, J.; MERRY, F.; PENA - CLAROS, M.; ZWEEDE, J.. Timber production in selectively logged tropical forests in South America. Front. Ecol. Environ., v.5, p.213-216, 2007.

PEÑA - CLAROS, M.; FREDERICKSEN, T. S.; ALARCO'N, A.; BLATE, G. M.; CHOQUE, U.; LEAÑO, C.; LICONA, J. C.; MOSTACEDO, B.; PARIONA, W.; VILLEGAS, Z.; PUTZ, F. E. 2008. Beyond reduced - impact logging: Silvicultural treatments to increase growth rates of tropical trees. Forest Ecology and Management. 256, 1458-1467.

PONTES, S. M. A; AFONSO, D. G.; NASCIMENTO, D. L.. Análise comparativa das propriedades físico-mecânicas da madeira de galho e fuste de 02 espécies florestais com potencial madeireiro. In: CONGRESSO FLORESTAL, 4. Anais. Curitiba, 2012. p.24-32.

SABOGAL, C.; ALMEIDA, E. de; MARMILLORD D.; CARVALHO, J. O. P.. Silvicultura na Amazônia Brasileira: avaliação de experiências e recomendações para implementação e melhorias dos sistemas. Belém: CIFOR, 2006.

SILVA, S. M. A.; SILVA, J. N. M.; BAIMA, A. M. V.; LOBATO, N M.; THOMPSON, I. S.; COSTA FILHO, P. P.. Impacto da exploração madeireira em floresta de terra firme no município de Mojú, estado do Pará. In: SILVA, J. N. M.; CARVALHO, J. O. P.; YARED, J. A. G.. A silvicultura na Amazônia Oriental: contribuições do projeto Embrapa/DFID. Belém: Embrapa Amazônia Oriental, 2001.

SILVA, R. P.; NAKAMURA, S.; AZEVEDO, C. P.; CHAMBERS, J.; ROCHA, R. M.; PINTO, A. C. M.; SANTOS, J.; HIGUCHI, N.. Uso de banda dendrométrica na definição de padrões de crescimento individual em diâmetro de árvores da bacia do rio cuieiras. Acta Amazônica, Manaus, v.33, n.1, p.67-84, 2003.

SILVA, E. N.; SANTANA, A. C.. Modelos de regressão para estimação do volume de árvores comerciais, em florestas de Paragominas. Revista Ceres, Viçosa, v.61, n.5, p.631-636, 
2014.

SCHONGART, J.; ORTHMANN, B.; HENNENBERG, K. J.; POREMBSKI, S.; WORBES, M.. Climate-growth relationships of tropical tree species in West Africa and their potential for climate reconstruction. Global Change Biology, v.12, p.11391150, 2006.

THAINES, F.; BRAZ, E. M; MATTOS, P. P.; THAINES, A. A. R.. Equações para estimativa de volume de madeira para a região da bacia do rio Ituxi, Lábrea, AM. Pesquisa Florestal Brasileira, Colombo, v.30, n.64, p.283-289, 2010.

UHL, C.; BARRETO, P.; VERISSIMO, A.; BARROS, A. C.; AMARAL, P.; VIDAL, E.; SOUZA JR, C.. Uma Abordagem integrada de pesquisa sobre o manejo dos recursos naturais na Amazônia. In: BARROS, A. C.; VERÍSSIMO, A.. A expansão da atividade madeireira na Amazônia: impactos e perspectivas para o desenvolvimento do setor florestal no Pará. 2 ed. Belém: Imazon, 2002. p.143-166.

VATRAZ, S.; CARVALHO, J. O. P.; GOMES, J. M.; TAFFAREL, M.; FERREIRA, J. E. R.. Efeitos de tratamentos silviculturais sobre o crescimento de Laetia procera (Poepp.) Eichler em Paragominas, PA, Brasil. Scientia Forestalis, Piracicaba, v.40, n.93, p.95-102, 2012.

WADSWORTH, F. H.; ZWEEDE, J. C.. Liberation: acceptable production of tropical forest timber. Forest Ecology and Management, v233, p.45-51, 2006.

A CBPC - Companhia Brasileira de Produção Científica (CNPJ: 11.221.422/0001-03) detém os direitos materiais desta publicação. Os direitos referem-se à publicação do trabalho em qualquer parte do mundo, incluindo os direitos às renovações, expansões e disseminações da contribuição, bem como outros direitos subsidiários. Todos os trabalhos publicados eletronicamente poderão posteriormente ser publicados em coletâneas impressas sob coordenação da Sustenere Publishing, da Companhia Brasileira de Produção Científica e seus parceiros autorizados. Os (as) autores (as) preservam os direitos autorais, mas não têm permissão para a publicação da contribuição em outro meio, impresso ou digital, em português ou em tradução. 